\title{
Validity and reliability of intra-oral and plaster models' photographs in the assessment of Little's Irregularity Index, tooth-size-arch-length discrepancy and Bolton's analysis
}

\section{Wael Al-Rasheed \\ Damascus University}

\section{Amer M Owayda}

Damascus University

Mohammad Y Hajeer ( $\nabla$ myhajeer@gmail.com )

University of Damascus Dental School https://orcid.org/0000-0003-0640-1297

Tarek Z Khattab

University of Hama

Rashad MT Murad

Damascus University

Wael Almahdi

Damascus University

Research article

Keywords: Intraoral photographs, Little's Irregularity Index, tooth-size-arch-length discrepancy, Bolton's analysis, digital method.

Posted Date: January 16th, 2020

DOI: https://doi.org/10.21203/rs.2.21031/v1

License: (c) (i) This work is licensed under a Creative Commons Attribution 4.0 International License. Read Full License 


\section{Abstract}

Background Dental impressions have been required to obtain proper study models. This procedure is a time- and labor-consuming for the orthodontist and could be exhausting to the patient especially when braces are fitted in the context of a research project. This study aimed to assess the accuracy, reliability, and reproducibility of using intraoral photographs and plaster models' photographs in measuring Little's Irregularity Index (LII), tooth-size-arch-length discrepancy (TSALD) and Bolton's ratios.

Methods Fifty-two dental arches of 26 patients were included in this study. Plaster models, occlusal intraoral photographs and photographs of the collected plaster models were obtained for each patient. Then, LII, TSALD and Bolton's ratios were measured using a manual caliper for plaster models' measurements and a software-based on-screen method for the photographs.

Results The intraclass correlation coefficients (ICCs) of measurements made on intraoral photographs and photographs of plaster models were high (ranging from 0.90 to 0.99 and from 0.88 to 0.99 , respectively) indicating a high level of agreement with the gold standard measurements. In addition, the differences were insignificant. The intra-/inter-examiner ICCs ranged from 0.90 to $0.99 / 0.92$ to 0.99 and from 0.85 to $0.99 / 0.88$ to 0.98 for plaster models and intraoral photographs of the dental arches, respectively. The analysis of reproducibility of capturing intraoral photographs of the dental arches in two different occasions showed high ICCs ranging from 0.96 to 0.99 with almost no significant differences between repeated measurements $(P>0.05)$.

Conclusion LII, TSALD, and Bolton's overall and partial ratios can be measured from intraoral photographs of the dental arches with high accuracy, reliability, and reproducibility. Therefore, this methodology can be suggested for use in research projects when multiple records of the dental arches are required instead of depending on time- and labor-consuming procedures of ordinary dental impressions.

\section{Background}

The general trend in the orthodontic practice is to become digital in many aspects. ${ }^{1}$ Since the $1980 \mathrm{~s}$, digital photographs have been available and play a principal role in the orthodontic practice for documentation and diagnosis purposes. ${ }^{2}$ Now photographs has an important role in teaching, scientific research, and medical examination. ${ }^{3}$

Successful orthodontic treatment is based on a comprehensive diagnosis and treatment planning. A few of the fundamental factors in the diagnosis are the spacing condition, teeth size, arch form and dimensions, as well as the tooth-arch discrepancies. ${ }^{4}$ Intra-oral photographs' major role is to enable orthodontists to document and analyze the occlusal relationships as well as the dental and soft-tissue features in order to arrive at a good diagnosis and an appropriate treatment planning. ${ }^{2}$ 
In 1975, Robert Little developed Little's irregularity index (LII). The index was proposed to assess teeth irregularity, crowding, relapse, and alignment of the anterior teeth as it measures the linear displacements in the horizontal plane between contact points of anterior teeth, ignoring vertical displacement, from the mesial surface of one canine to the contralateral one. The sum of the 5 liner measurements of displacements was the LII score. The higher the index value, the more severe irregularity of the teeth was. ${ }^{5}$ LII has been originally developed for mandibular incisors to study relapse; however, researchers have used it to assess upper and lower incisors irregularity. ${ }^{6,7}$

Tooth-size-arch-length discrepancy (TSALD) is widely used on study models to assess the level of harmony between tooth size and the supporting basal bone. ${ }^{8}$ Bolton analysis is another important measurement used to identify disharmony between maxillary and mandibular tooth size which is considered an important factor to ensure the success of orthodontic treatment. With the application of the suggested formulas, the overall ratio should be $91.3 \%$ ( \pm 1.91$)$ and the partial (anterior) ratio should be $77.2 \%( \pm 1.65) .{ }^{9}$

Assessment of the LII scores, TSALD, Bolton analysis has been performed by the majority of previous studies using plaster models and calipers in a direct manner., 5 Others have measured previous variables indirectly using 2-dimensional (2D) and 3-dimensional (3D) methods. 2D methods have included 2D scans of plaster models or $2 \mathrm{D}$ images of the occlusal views. The obtained images have been then analyzed either manually ${ }^{10}$ or on-screen using dedicated software. ${ }^{11,12} 3 \mathrm{D}$ methods have included digital models and have been used by several researchers. ${ }^{1,4,13-19}$ Although the wealth of knowledge of 3D methods provide, they require the use of 3D imaging techniques with the resultant additional costs, time and labor.

Many studies have used 2D digital images of poured plaster models to perform software-based measurements of tooth movement during active treatment but these studies have not reported the accuracy and reproducibility of their methods. ${ }^{20-22}$ Dental impressions have been required to obtain proper study models. This procedure is a time- and labor-consuming for the orthodontist and could be exhausting to the patient. When braces are fitted, impression taking becomes a difficult task and if several impressions are required in the context of a research project, this would impose an additional burden to patients and researchers. Therefore, taking intra-oral images of dental arches instead of impressions seems to be a very convenient alternative.

Validity and reliability of measurements made on photographs of study models have been evaluated in previous reports. ${ }^{23,24}$ However, it seems to be that there is only one paper in the literature with the aim of validating the use of intra-oral images of the dental arches for performing dental measurements. ${ }^{25}$ They found that the analysis of LII using photographs was valid. However, the practicability of their suggested method of imaging was questionable and their evaluation was only confined to the LII, which is not the only variable that is used in our ordinary plaster model analysis. 
The primary aim of the current work was to evaluate the validity, reliability, and repeatability of measurements made directly on intra-oral photographs compared to those made on poured plaster models in the assessment of the LII, TSALD, and Bolton ratios. As a secondary aim, the comparisons were also accomplished with those measurements made on photographs taken of the corresponding poured plaster models.

\section{Methods}

This trial was registered at Clinical Trials.gov (Identifier: NCT03648515). After Obtaining the Ethical Approval from the Local Ethics Research Committee at the University of Damascus, 143 patients who sought orthodontic treatment at the Orthodontic Department of Damascus University Dental School were examined during January, February and March in 2018. Twenty-six of them were randomly selected with the following inclusion criteria: complete permanent dentition without any big carious lesions or fixed prosthetics or shape and size disturbances (regardless third molars) associated with upper and lower crowded arches. Upper and lower orthodontic models were obtained from "Additional Silicone" Impressions (Zetaplus, Zhermack dental, Italy) for each patient then poured with dental plaster (Elite ortho type 3, Zhermack dental, Italy).

Occlusal intra-oral photographs were taken with DSLR camera (EOS 5D Mark III camera; Canon, USA) with a dedicated lens (Canon EF 100 mm; f/2.8L; Macro IS USM) and a Ring flash (Yongnuo YN14-EX TTL Macro Ring Light Flash, USA) using an ETTL mode and a flash control ratio of 1:1. Photographs were taken at two occasions with an interval of two weeks by two third-year MSc students (A.O., W.R.) at the Department of Orthodontics using the following settings for intra-oral photographing: Manual Program mode, ISO 100, shutter speed 1/250 second, focus distance $35 \mathrm{~cm}$, zoom ratio 2:1.

Photographs were only accepted for inclusion in the current study when they showed the labial and lingual surfaces of the anterior teeth according to the clinical guide that mentioned by Almasoud and Bearn. ${ }^{25}$ A ruler was fixed by a double-sided adhesive on a lip expander (Retract EEZ ${ }^{\mathrm{T}}$, Ortho Technology, USA) for calibration purposes and used an occlusal mirror (HAHNENKRATT photo mirror form 2, E. HAHNENKRATT GmbH, Germany) as shown in Figs. 1A and 2. Study models were photographed using a camera mounted on a stand (LPL 6000 Series Medium Format Enlargers, KHB Photografix, Welland, Ontario, Canada) with the same previous settings except for the distance that was set at $42 \mathrm{~cm}$ as shown in Fig. 1B.

Validity of intra-oral photographs and plaster models' photographs.

Measurements of LII, the sum of teeth sizes (STS), basal bone length (BBL), TSALD, Bolton's analysis were undertaken on (1) plaster models, (2) calibrated intra-oral photographs of the dental arches and (3) photographs of the same plaster models. Then the measurements made on photographs were compared against the gold standard values (i.e., the plaster models' measurements).

Intra- and inter-observer reliability of measurements 
All measurements were repeated after 2 weeks by the same examiner (A.O.) to determine intra-observer reliability and by another examiner (W.R.) to determine inter-observer reliability.

Reproducibility of the procedure of intra-oral imaging

Another set of intra-oral photographs were taken by the first examiner (A.O.) and the measurements were performed again to evaluate the reproducibility of the procedure of intra-oral imaging.

All measurements on photographs were recorded using Image-J software version 1.71 (developed by Werner Bailer, Austria University of Applied Sciences, Hagenberg, Austria). Measurements on study models were made using dental manual caliper (Zuricher $130 \mathrm{~mm}$, Medesy, Italy) with a precision of $0.1 \mathrm{~mm}$.

\section{Statistical analysis}

IBM ${ }^{\circledR}$ SPSS ${ }^{\circledR}$ program V20 was used to test the Normality of data using the Kolmogorov-Smirnov test. The correlation between measurements was tested using the intraclass correlation coefficient (ICC) and the paired t-test to determine the differences.

\section{Results}

Validity and reliability of measurements made on intra-oral images

The validity and reliability of measurements made on intra-oral photographs by the Examiner $A$ and $B$ are given in Tables 1 and 2, respectively. All measurements showed high ICCs when compared with the gold standard readings and they were greater than $90 \%$. For the first examiner, mean differences between measurements made on intra-oral photographs versus the gold standard values were between $0.10 \mathrm{~mm}$ for TSALD values and $0.45 \mathrm{~mm}$ for the sum of teeth size. All variables showed a statistical significance except TSALD and overall Bolton value, whereas for the second examiner, the highest difference was $0.27 \mathrm{~mm}$ for partial Bolton value and the differences were not statistically significant.

Validity and reliability of measurements made on plaster models' images

The evaluation of measurements made on images taken of poured plaster models compared to the gold standard measurements is given in Table 3. High level of agreement was found for all variables with ICCs more than 0.88 and mean differences ranging from $0.14 \mathrm{~mm}$ for the basal bone length to $0.48 \mathrm{~mm}$ for the sum of teeth size with no statistically significant differences for all variables except for the LII and the TSALD measurements $(P<0.001, P=0.026$; respectively $)$.

Intra- and inter-examiner reliability of the different measuring techniques

Intra-examiner reliability of measurements made on plaster models is given in Table 4. ICCs were greater than 0.90 for all measurements and the mean differences between repeated measurements ranged from 
$0.17 \mathrm{~mm}$ for LII to 0.33 for partial Bolton value with a significant difference found for the LII and TSALD $(P<0.001$ for both variables $)$

The intra-examiner reliability of measurements made on intra-oral images of dental arches showed a high level of agreement with ICCs being greater than 0.85 , whereas the mean differences between the repeated measurements ranged from $0,04 \mathrm{~mm}$ for LII to $0.18 \mathrm{~mm}$ for the sum of teeth size. All these differences were not statistically significant as shown in Table 5 . This indicated a high competency between the first and second measurements on the same intra-oral photographs and high intra-examiner reliability.

The analysis of inter-examiner reliability of plaster models' measurements and those of intra-oral photos' showed a high ICCs that ranged between 0.92 for partial Bolton ratio and 0.99 for STS and LII, indicating a high level of agreement between both examiners. The mean differences between the two examiners' measurements when evaluating plaster models ranged from $0.08 \mathrm{~mm}$ for LII to $0.24 \mathrm{~mm}$ for partial Bolton ratio with no significant differences except for the sum of teeth size and LII ( $p=0.041$ and $p<$ 0.001 , respectively; Table 6 ). On the other hand, the mean differences when evaluating intra-oral photographs ranged from $0.12 \mathrm{~mm}$ for overall Bolton ratio to $0.27 \mathrm{~mm}$ for TSALD with no significant differences observed for all variables (Table 7). This indicated a high consistency between the first and second examiners.

Reproducibility of measurements made on intra-oral images of the dental arches.

The evaluation of measurements made on the first set of intra-oral images compared to the second set of the same dental arches showed a high level of agreement for all variables. ICCs were more than 0.96 and the mean differences between repeated measurements ranged from $0.03 \mathrm{~mm}$ for the basal bone length to 0.22 for the partial Bolton ratio with no statistically significant differences for all variables except for the LII $(P=0.018)$ as shown in Table 8. 
Table 8

Reproducibility of measurements made on intraoral photographs of the dental arches at two different occasions.

\section{Table 1: Validity and reliability of measurements made on intraoral photographs of the dental arches compared to those made on plaster models (Examiner A)}

\begin{tabular}{lclllll} 
Variable & ICC & $\begin{array}{l}\text { Mean } \\
\text { difference }\end{array}$ & SD & P-value & \multicolumn{2}{c}{$95 \%$ Confidence Interval } \\
\hline STS & 0.98 & -0.45 & 0.91 & $0.011^{\star}$ & -0.70 & -0.19 \\
BBL & 0.98 & -0.39 & 0.40 & $0.002^{\star \star \star}$ & -0.50 & -0.27 \\
$\begin{array}{l}\text { TSALD } \\
\text { value }\end{array}$ & 0.90 & -0.10 & 0.95 & 0.652 & -0.32 & -0.20 \\
\hline LII & 099 & -0.16 & 0.35 & $0.002^{\star \star}$ & -0.25 & -0.06 \\
$\begin{array}{l}\text { Partial } \\
\text { Bolton }\end{array}$ & 0.98 & -0.24 & 0.51 & $0.002^{\star \star}$ & -0.46 & -0.03 \\
$\begin{array}{l}\text { Overall } \\
\text { Bolton }\end{array}$ & 0.97 & -0.40 & 0.56 & 0.691 & -0.28 & 0.19
\end{tabular}

$*: p<0.05, * *: p<0.01, * * *: p<0.001$, ICC: Intraclass correlation coefficient, SD: standard deviation, TSALD: tooth size arch length discrepancy, LII: little irregularity index, BLL: basal bone length, STS: sum of teeth sizes.

Table 2: Validity and reliability of measurements made on intraoral photographs of the dental arches compared to those made on plaster models (Examiner B)

\begin{tabular}{|lllllll|}
\hline Variable & ICC & $\begin{array}{l}\text { Mean } \\
\text { difference }\end{array}$ & SD & P-value & \multicolumn{2}{c|}{$95 \%$ Confidence Interval } \\
\hline STS & 0.99 & 0.10 & 0.59 & 0.852 & -0.15 & 0.18 \\
\hline BBL & 0.99 & 0.12 & 0.32 & 0.385 & -0.05 & 0.13 \\
$\begin{array}{l}\text { TSALD } \\
\text { value }\end{array}$ & 0.95 & -0.16 & 0.65 & 0.792 & -0.20 & 0.15 \\
\hline LII & 0.99 & -0.12 & 0.26 & 0.127 & -0.13 & 0.16 \\
\hline $\begin{array}{l}\text { Partial } \\
\text { Bolton }\end{array}$ & 0.92 & -0.27 & 1.13 & 0.236 & -0.74 & 0.19 \\
$\begin{array}{l}\text { Overall } \\
\text { Bolton }\end{array}$ & 0.94 & -0.24 & 0.79 & 0.576 & -0.42 & 0.24 \\
\hline
\end{tabular}

ICC: Intraclass correlation coefficient, SD: standard deviation, TSALD: tooth size arch length discrepancy, LII: little irregularity index, BLL: basal bone length, STS: sum of teeth sizes. 
Table 1: Validity and reliability of measurements made on intraoral photographs of the dental arches compared to those made on plaster models (Examiner A)

Table 3: Validity and reliability of measurements made on photographs of plaster models compared to those made on plaster models (Examiner A)

\begin{tabular}{|c|c|c|c|c|c|c|}
\hline Variable & ICC & $\begin{array}{l}\text { Mean } \\
\text { difference }\end{array}$ & SD & P-value & $\begin{array}{l}95 \% 0 \\
\text { interv } \\
\text { differ }\end{array}$ & \\
\hline STS & 0.93 & -0.48 & 1.81 & 0.063 & -0.99 & 0.02 \\
\hline BBL & 0.97 & -0.14 & 1.19 & 0.382 & -0.48 & 0.18 \\
\hline $\begin{array}{l}\text { TSALD } \\
\text { value }\end{array}$ & 0.88 & -0.33 & 1.04 & $0.026^{\star}$ & -0.62 & -0.04 \\
\hline LII & 0.99 & -0.19 & 0.29 & $<0.001^{* * *}$ & -0.28 & -0.11 \\
\hline $\begin{array}{l}\text { Partial } \\
\text { Bolton }\end{array}$ & 0.94 & -0.28 & 0.96 & 0.155 & -0.68 & 0.11 \\
\hline $\begin{array}{l}\text { Overall } \\
\text { Bolton }\end{array}$ & 0.96 & -0.20 & 0.66 & 0.510 & -0.37 & 0.19 \\
\hline
\end{tabular}

*: $p<0.05, * * *: p<0.001$, ICC: Intraclass correlation coefficient, SD: standard deviation, TSALD: tooth size arch length discrepancy, LII: little irregularity index, BLL: basal bone length, STS: sum of teeth sizes.

Table 4: Intra-examiner reliability of measurements made on plaster models (Examiner A)

\begin{tabular}{|c|c|c|c|c|c|c|}
\hline Variable & ICC & $\begin{array}{l}\text { Mean } \\
\text { difference }\end{array}$ & SD & P-value & $\begin{array}{l}95 \% \mathrm{C} \\
\text { interv } \\
\text { differ }\end{array}$ & \\
\hline STS & 0.90 & -0.19 & 2.50 & 0.578 & -0.89 & 0.50 \\
\hline BBL & 0.91 & 0.24 & 2.36 & 0.463 & -0.42 & 0.91 \\
\hline $\begin{array}{l}\text { TSALD } \\
\text { value }\end{array}$ & 0.94 & -0.27 & 0.66 & $\hat{0}_{0.001 * \star \star}$ & -0.46 & -0.08 \\
\hline LII & 0.99 & -0.17 & 0.24 & $\begin{array}{l}<.001^{\star * \star} \\
\end{array}$ & -0.24 & -0.11 \\
\hline $\begin{array}{l}\text { Partial } \\
\text { Bolton }\end{array}$ & 0.91 & -0.33 & 1.2 & 0.193 & -0.85 & 0.18 \\
\hline $\begin{array}{l}\text { Overall } \\
\text { Bolton }\end{array}$ & 0.96 & -0.20 & 0.66 & 0.150 & -0.48 & 0.07 \\
\hline
\end{tabular}

***: $p<0.001$, ICC: Intraclass correlation coefficient, SD: standard deviation, TSALD: tooth size arch length discrepancy, LII: little irregularity index, BLL: basal bone length, STS: sum of teeth sizes. 
Table 1: Validity and reliability of measurements made on intraoral photographs of the dental arches compared to those made on plaster models (Examiner A)

Table 5: Intra-examiner reliability of measurements made on intra-oral photographs of the dental arches (Examiner $\mathrm{A})$

\begin{tabular}{lclcccc} 
Variable & ICC & $\begin{array}{l}\text { Mean } \\
\text { difference }\end{array}$ & SD & \multicolumn{2}{c}{ P-value } & \multicolumn{2}{l}{$\begin{array}{l}95 \% \text { Confidence } \\
\text { Interval }\end{array}$} \\
\hline STS & 0.98 & 0.18 & 0.94 & 0.159 & -0.07 & 0.45 \\
\hline BLL & 0.98 & 0.07 & 0.89 & 0.543 & -0.17 & 0.32 \\
\hline $\begin{array}{l}\text { TSALD } \\
\text { value }\end{array}$ & 0.85 & 0.11 & 1.24 & 0.524 & -0.23 & 0.46 \\
\hline LII & 0.98 & 0.04 & 0.43 & 0.487 & -0.08 & 0.16 \\
\hline $\begin{array}{l}\text { Partial } \\
\text { Bolton }\end{array}$ & 0.99 & 0.12 & 0.41 & 0.947 & -0.16 & 0.17 \\
$\begin{array}{l}\text { Overall } \\
\text { Bolton }\end{array}$ & 0.98 & -0.10 & 0.36 & 0.173 & -0.25 & 0.04 \\
\hline
\end{tabular}

ICC: Intraclass correlation coefficient, SD: standard deviation, TSALD: tooth size arch length discrepancy, LII: little irregularity index, BLL: basal bone length, STS: sum of teeth sizes.

Table 6: Inter-examiner reliability of measurements made on plaster models (Examiners A and B)

\begin{tabular}{|c|c|c|c|c|c|c|}
\hline Variable & ICC & $\begin{array}{l}\text { Mean } \\
\text { difference }\end{array}$ & SD & P-value & $\begin{array}{l}95 \% \\
\text { Confic } \\
\text { interv }\end{array}$ & \\
\hline STS & 0.99 & -0.10 & 0.35 & $0.041^{*}$ & -0.20 & $\begin{array}{l}< \\
0.01\end{array}$ \\
\hline BBL & 0.97 & -0.20 & 0.21 & 0.338 & -0.30 & 0.25 \\
\hline $\begin{array}{l}\text { TSALD } \\
\text { value }\end{array}$ & 0.98 & -0.12 & 0.38 & 0.174 & -0.18 & 0.03 \\
\hline LII & 0.99 & -0.08 & 0.18 & $<.001^{\star * *}$ & -0.13 & -0.03 \\
\hline $\begin{array}{l}\text { Partial } \\
\text { Bolton }\end{array}$ & 0.92 & -0.24 & 1.09 & 0.271 & -0.69 & 0.20 \\
\hline $\begin{array}{l}\text { Overall } \\
\text { Bolton }\end{array}$ & 0.95 & -0.22 & 0.78 & 0.926 & -0.34 & 0.31 \\
\hline
\end{tabular}

*: $p<0.05, * * *: p<0.001$, ICC: Intraclass correlation coefficient, SD: standard deviation, TSALD: tooth size arch length discrepancy, LII: little irregularity index, BLL: basal bone length, STS: sum of teeth sizes. 
Table 1: Validity and reliability of measurements made on intraoral photographs of the dental arches compared to those made on plaster models (Examiner A)

Table 7: Inter-examiner reliability of measurements made on intraoral photographs of the dental arches (Examiners $A$ and $B$ )

\begin{tabular}{|llllllll}
\hline Variable & ICC & $\begin{array}{l}\text { Mean } \\
\text { difference }\end{array}$ & SD & P-value & \multicolumn{3}{l}{$\begin{array}{l}95 \% \\
\text { Confidence } \\
\text { Interval }\end{array}$} \\
\hline STS & 0.98 & 0.21 & 0.99 & 0.124 & -0.06 & 0.49 \\
\hline BBL & 0.98 & 0.17 & 0.82 & 0.143 & -0.06 & 0.40 \\
$\begin{array}{l}\text { TSALD } \\
\text { value }\end{array}$ & 0.88 & 0.27 & 1.13 & 0.778 & -0.27 & 0.36 \\
LII & 0.98 & 0.19 & 0.46 & 0.150 & -0.03 & 0.22 \\
$\begin{array}{l}\text { Partial } \\
\text { Bolton }\end{array}$ & 0.97 & 0.14 & 0.58 & 0.696 & -0.19 & 0.28 \\
$\begin{array}{l}\text { Overall } \\
\text { Bolton }\end{array}$ & 0.97 & 0.12 & 0.53 & 0.635 & -0.17 & 0.28
\end{tabular}

ICC: Intraclass correlation coefficient, SD: standard deviation, TSALD: tooth size arch length discrepancy, LII: little irregularity index, BLL: basal bone length, STS: sum of teeth sizes.

Table 8: Reproducibility of measurements made on intraoral photographs of the dental arches at two different occasions

\begin{tabular}{|c|c|c|c|c|c|c|}
\hline Variable & ICC & $\begin{array}{l}\text { Mean } \\
\text { difference }\end{array}$ & SD & P-value & \multicolumn{2}{|c|}{ 95\% Confidence Interval } \\
\hline STS & 0.99 & -0.08 & 0.49 & 0.212 & -0.22 & 0.05 \\
\hline BBL & 0.99 & -0.03 & 0.43 & 0.612 & -0.15 & 0.09 \\
\hline $\begin{array}{l}\text { TSALD } \\
\text { value }\end{array}$ & 0.98 & -0.05 & 0.42 & 0.347 & -0.17 & 0.06 \\
\hline LII & 0.99 & 0.07 & 0.23 & $0.018^{*}$ & 0.01 & 0.14 \\
\hline $\begin{array}{l}\text { Partial } \\
\text { Bolton }\end{array}$ & 0.99 & -0.22 & 0.56 & 0.055 & -0.005 & 0.46 \\
\hline $\begin{array}{l}\text { Overall } \\
\text { Bolton }\end{array}$ & 0.96 & -0.19 & 0.60 & 0.130 & -0.06 & 0.44 \\
\hline
\end{tabular}


When a scan or photocopy of the plaster model is properly taken, the produced photograph is expected to be perpendicular to the occlusal plane. This matter does not exist with the intra-oral photography of the dental arches using hand-held cameras and may introduce errors of projection. The angulation at which the intra-oral photograph is taken may vary so that a vertical component of the contact points displacement can be introduced to the measurement. ${ }^{25}$ Additionally, photographs may also have errors of magnification, so the calibration process (correction of magnification) must be taken into account before any measurement is carried out on a digital photo.

The study model measurements were considered as the gold standard for testing photograph-based measurements validity. Indeed, manual measuring on study models may suffer from some inherent errors (e.g., vibrations and sometimes calipers cannot reach the exact interproximal contact point of a tooth when that tooth is in contact with other teeth) $.4,26$

Differences between the evaluated two methods of measuring that were greater than $0.25 \mathrm{~mm}$ were considered clinically important for small measurements (e.g., LII) and the threshold of clinically significant differences was raised to $1 \mathrm{~mm}$ for those greater measurements in the orthodontic study model analyses (e.g., TSALD, BOLTON ratios and sum of tooth size) .

In contrast to the current study, the previous papers ${ }^{23-25}$ tested the validity of photographs when measuring LII only. Orthodontic diagnosis and treatment planning depends on several dental and alveolar analyses and the assessment of LII solely is not enough for decision making and outcomes' analysis in the daily practice. Therefore, this study was accomplished to cover a wide spectrum of analyses that evaluate dental arches in the context of orthodontic evaluation.

Almasoud and Bearn used a millimeter ruler placed with wax onto the cusp tips of the premolars in the same level of the occlusal plane crossing the dental arch horizontally. This ruler helped in correcting the magnification of intra-oral photographs but was not practically easy to use since the applied wax may have not provided good and stable contact with the teeth as well as being cumbersome to the evaluated patients. Additionally, the fixation of the ruler at the middle of the dental arch prevented the ability of measurements in the posterior regions, so less chance to apply several dental arch analyses. Therefore, in the current trial, the ruler was fixed on the periphery of the lip retractor enabling the operator to take photos without any additional time-wasting procedures.

Validity and reliability of measurements made on intra-oral images

The differences in teeth sizes, basal bone length, LII, and partial Bolton measured on intra-oral images by Examiner A were statically significant when compared to those obtained from study models. However, the differences were equal to or less than $0.25 \mathrm{~mm}$ for the LII and $0.45 \mathrm{~mm}$ for the other variables which appeared to be of no clinical importance. On the other hand TSALD, overall Bolton value that measured by Examiner $A$ and all variables measured by Examiner $B$ did not show any statistically significant differences from those obtained from study models indicating that all measurements on intra-oral photographs were of a high, and sometimes a very good, level of agreement with those of plaster models. 
The current findings are similar to those of Almasoud and Bearn who evaluated only the LII measurement. Nevertheless, the current $95 \%$ confidence intervals of mean differences were narrower than those of Almasoud and Bearn. This may be due to differences in the calibration method, camera and lens settings, or mirror reflecting properties that may have affected picture resolution.

Validity and reliability of measurements made on plaster models' images

The comparison between measurements made on plaster models and the corresponding images of these study models showed high ICCs which were greater than 0.88 and the differences were less than $0.19 \mathrm{~mm}$ for LII and $0.48 \mathrm{~mm}$ for the other variables. Since the differences in the LII and TSALD measurements were less than the aforementioned clinical thresholds, good validity and reliability could be inferred. These findings are consistent with those of Almasoud and Bearn, Mushtaq et al and Tran et al who employed digital images of study models in their assessments. ${ }^{23-25}$ Tran et al reported that the assessment of LII in Class II crowded mandibular arches was very reliable and valid; unfortunately, they presented only correlation coefficients without performing significance testing. ${ }^{24}$

Intra- and inter-examiner reliability of the different measuring techniques

The analysis of intra-examiner reliability of measurements made on plaster models revealed high ICCs. On the other hand, significant differences smaller than $0.27 \mathrm{~mm}$ (and $0.17 \mathrm{~mm}$ for LII) were found between the repeated measurements of one examiner (i.e. Examiner A) regarding LII and TSALD values but these differences could be neglected since they do not affect the clinical decision.

The intra-examiner reliability of measurements made on intra-oral images of dental arches showed high ICCs and all obtained values were greater than 0.85 . In addition, mean differences were not significantly different between the two sets of data. This indicated a high agreement between the first and second measurements and high intra-examiner reliability.

The analysis of inter-examiner reliability of plaster models' measurements and those of intra-oral photos' showed high ICCs that ranged between 0.92 and 0.99 . Significant differences with p-values less than 0.05 were found in teeth size and LII variables between the two examiners (i.e. Examiner A and Examiner B) on plaster models but these differences were less than $0.10 \mathrm{~mm}$ which did not have any clinical importance. No significant differences were identified between the two examiners regarding measurements made on intra-oral photographs. This indicated a high level of agreement between the first and second examiners when using the same intra-oral photographs and high inter-examiner reliability. This is similar to the previous reports by Almasoud and Tran. ${ }^{24,25}$

Actually, intra-oral photographs method were better than direct measurement on study models in terms of intra-/inter-examiner reliability, particularly for the TSALD analysis due to obtained high ICC values. A similar conclusion was arrived at by Almasoud and Bearn regarding LII measurement. This can be attributed to the error introduced in manual measuring if any vibration occurs and secondly to the 
inability of calipers' heads to rest at the exact interproximal contact points of neighboring teeth when they are in close contact or overlapped.

Reproducibility of measurements made on intra-oral images

The comparison between results obtained from the first and second intra-oral photographs showed a significant difference just for LII but the mean difference was lower than the aforementioned clinical threshold (i.e. $0.25 \mathrm{~mm}$ for LII).

In the light of the current results, measurements on intra-oral photographs of the dental arches were very accurate, reliable and repeatable when performing dental arch analysis. Additionally, they are suggested to replace study models and eliminate the need for repeated impressions during orthodontic treatment with fixed appliances in the context of prospective research projects.

\section{Conclusions}

Measurements of Little's index of irregularity, tooth-size-arch-length discrepancy, partial and overall Bolton analysis performed on intra-oral images of the dental arches and images of study models were valid when compared to the gold standard measurements. Additionally, all the aforementioned measurements performed on intra-oral photographs and images of study models were reliable regarding the intra-/interobserver reliability and the whole procedure of capturing the dental arches was found reproducible.

\section{Declarations}

\section{Ethics approval and consent to participate:}

Ethical Approval was obtained from the Local Ethics Research Committee at the University of Damascus (Reference number: 21021262018-DEN). Patients were given information sheets and their written informed consents were obtained.

\section{Consent for publication:}

Not applicable.

\section{Availability of data and materials:}

The datasets used and/or analyzed during the current study are available from the corresponding author on reasonable request.

\section{Competing interests:}

The authors declare that they have no competing interests.

\section{Funding:}


No funding.

\section{Authors' contributions:}

WR and AO collected, analyzed and interpreted the data, wrote, revised and did the final approval of the article. MYH designed this study, analyzed and interpreted the data, wrote, revised and did the final approval of the article. TZK participated in the study design, wrote, revised and did the final approval of the article. RM helped in data analysis, revised and did the final approval of the article. WM participated in supervising data collection, revised and did the final approval of the article.

\section{Acknowledgments:}

Not applicable.

\section{Abbreviations}

LII: Little's irregularity index.

TSALD: Tooth-size-arch-length discrepancy.

2D: 2-dimensional.

3D: 3-dimensional.

STS: The sum of teeth sizes.

BBL: Basal bone length.

ICC: Intraclass correlation coefficient.

\section{References}

1.

Stevens DR, Flores-Mir C, Nebbe B, Raboud DW, Heo G, Major PW. Validity, reliability, and reproducibility of plaster vs digital study models: comparison of peer assessment rating and Bolton analysis and their constituent measurements. Am j orthod dentofac orthop. 2006;129(6):794-803.

2.

Sreesan PB, Rahul CS, ST VF. Clinical Photography in Orthodontics. Int J Oral Health Med Res. 2016;3(2):71-5.

3. 
Manjunath S, Ragavendra RT, Setty SK, Jayalakshmi K. Photography in clinical dentistry-a review. Int J Dental Clin. 2011;3(2).

4.

Zilberman O, Huggare J, Parikakis KA. Evaluation of the validity of tooth size and arch width measurements using conventional and three-dimensional virtual orthodontic models. Angle Orthod. 2003;73(3):301-6.

5.

Little RM. The irregularity index: a quantitative score of mandibular anterior alignment. Am J Orthod. 1975;68(5):554-63.

6.

AlSayed Hasan MMA, Sultan K, Hamadah O. Low-level laser therapy effectiveness in accelerating orthodontic tooth movement: A randomized controlled clinical trial. Angle Orthod. 2016;87(4):499-504. 7.

Eslambolchi S, Woodside DG, Rossouw PE. A descriptive study of mandibular incisor alignment in untreated subjects. Am J Orthod Dentofac Orthop. 2008;133(3):343-53.

8.

Carey C. Linear arch dimension and tooth size: An evaluation of the bone and dental structures in cases involving the possible reduction of dental units in treatment. Am J Orthod. 1949;35(10):762-75.

9.

Bolton WA. Disharmony in tooth size and its relation to the analysis and treatment of malocclusion. Angle Orthod. 1958;28(3):113-30.

10.

Surbeck BT, Årtun J, Hawkins NR, Leroux B. Associations between initial, posttreatment, and postretention alignment of maxillary anterior teeth. Am J Orthod Dentofac Orthop. 1998;113(2):186-95.

11.

Goldberg Al, Behrents R, Oliver DR, Buschang PH. Facial divergence and mandibular crowding in treated subjects. Angle Orthod. 2012;83(3):381-8.

12.

Makki L, Ferguson DJ, Wilcko MT, Wilcko WM, Bjerklin K, Stapelberg R, et al. Mandibular irregularity index stability following alveolar corticotomy and grafting: A 10-year preliminary study. Angle Orthod. 2014;85(5):743-9.

13.

Brandão MM, Sobral MC, Vogel CJ. Reliability of Bolton analysis evaluation in tridimensional virtual models. Dent Press J Orthod. 2015;20(5):72-7.

14.

Bukhari SAA, Reddy KA, Reddy MR, Shah SH. Evaluation of virtual models (3Shape Ortho System) in assessing accuracy and duration of model analyses based on the severity of crowding. Saudi J Dent Res. 2017;8(1-2):11-8.

15. 
Correia GDC, Habib FAL, Vogel CJ. Tooth-size discrepancy: A comparison between manual and digital methods. Dent Press J Orthod. 2014;19(4):107-13.

16.

Czarnota J, Hey J, Fuhrmann R. Measurements using orthodontic analysis software on digital models obtained by 3D scans of plaster casts. J Orofac Orthop/Fortschritte der Kieferorthopädie. 2016;77(1):2230 .

17.

Keating AP, Knox J, Bibb R, Zhurov Al. A comparison of plaster, digital and reconstructed study model accuracy. J Orthod. 2008;35(3):191-201.

18.

Quimby ML, Vig KW, Rashid RG, Firestone AR. The accuracy and reliability of measurements made on computer-based digital models. Angle Orthod. 2004;74(3):298-303.

19.

Hajeer MY. Assessment of dental arches in patients with Class II division 1 and division 2 malocclusions using 3D digital models in a Syrian sample. Eur J Paed Dent. 2014;15(2):151-7.

20.

Alfawal AM, Hajeer MY, Ajaj MA, Hamadah O, Brad B. Evaluation of piezocision and laser-assisted flapless corticotomy in the acceleration of canine retraction: a randomized controlled trial. Head face medicine. 2018;14(1):4.

21.

Hassan SE, Hajeer M, Alali O, Kaddah A. The Effect of Using Self-ligating Brackets on Maxillary Canine Retraction: A Split-mouth Design Randomized Controlled Trial. J Contemp Dent Pract. 2016;17(6):496503.

22.

Jayachandran B, Padmanabhan R, Vijayalakshmi D, Padmanabhan J. Comparative evaluation of efficacy of self-ligating interactive bracket with conventional preadjusted bracket: A clinical study. Contemp Clin Dent. 2016;7(2):158.

23.

Mushtaq N, Tajik I, Baseer S. VALIDITY OF LITTLE'S. IRREGULARITY INDEX ON PHOTOCOPIED IMAGES OF DENTAL CASTS. Pakistan Oral Dent J. 2012;32(3).

24.

Tran AM, Rugh JD, Chacon JA, Hatch JP. Reliability and validity of a computer-based Little irregularity index. Am J Orthod Dentofac Orthop. 2003;123(3):349-51.

25.

Almasoud N, Bearn D. Little's irregularity index: photographic assessment vs study model assessment. Am J Orthod Dentofac Orthop. 2010;138(6):787-94.

26.

Grünheid T, Patel N, De Felippe NL, Wey A, Gaillard PR, Larson BE. Accuracy, reproducibility, and time efficiency of dental measurements using different technologies. Am J Orthod Dentofac Orthop. 2014;145(2):157-64. 
Figures
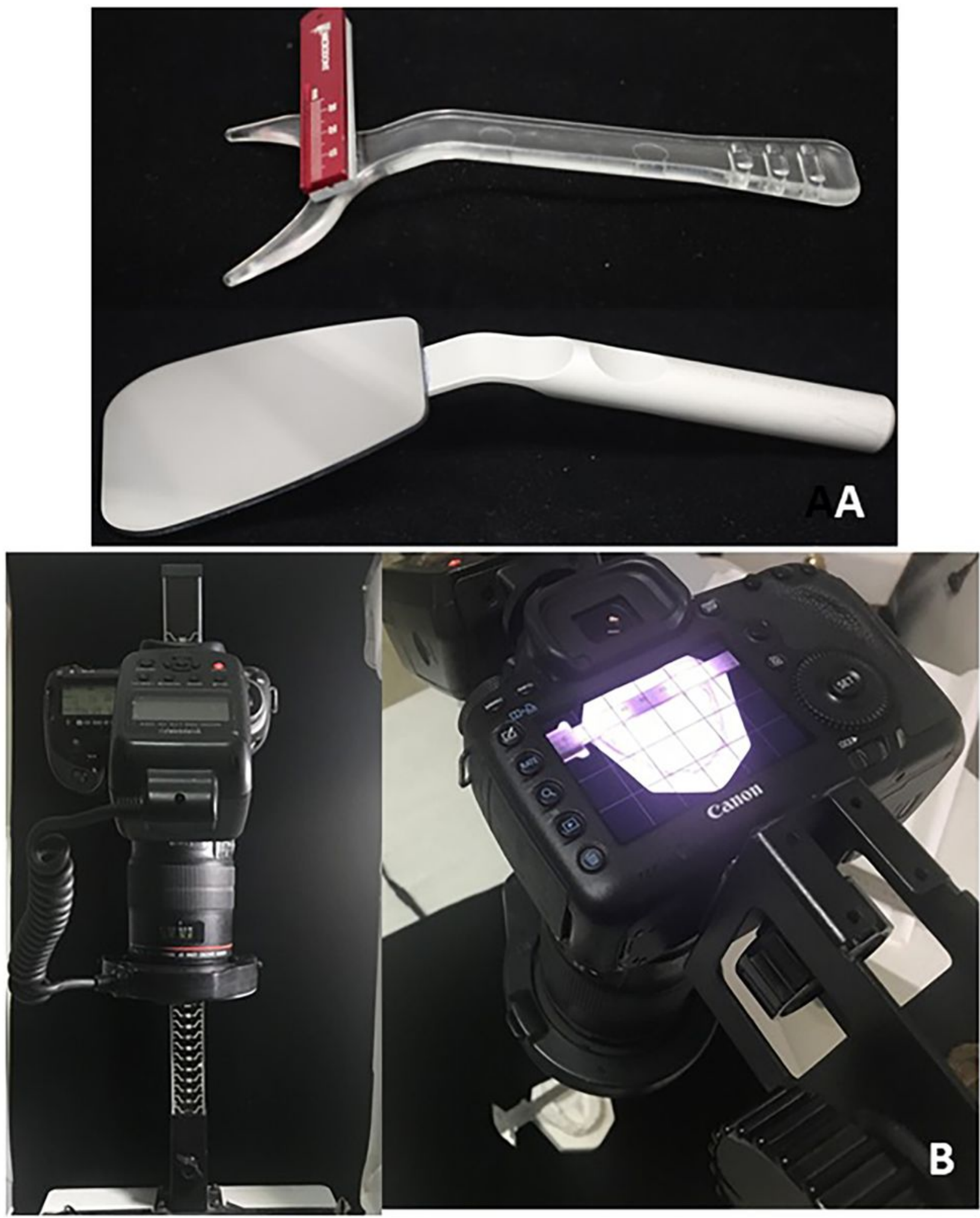

\section{Figure 1}

The employed lip retractor with a fixed ruler in addition to the occlusal mirror (A), the employed camera mounted on a stand (B). 


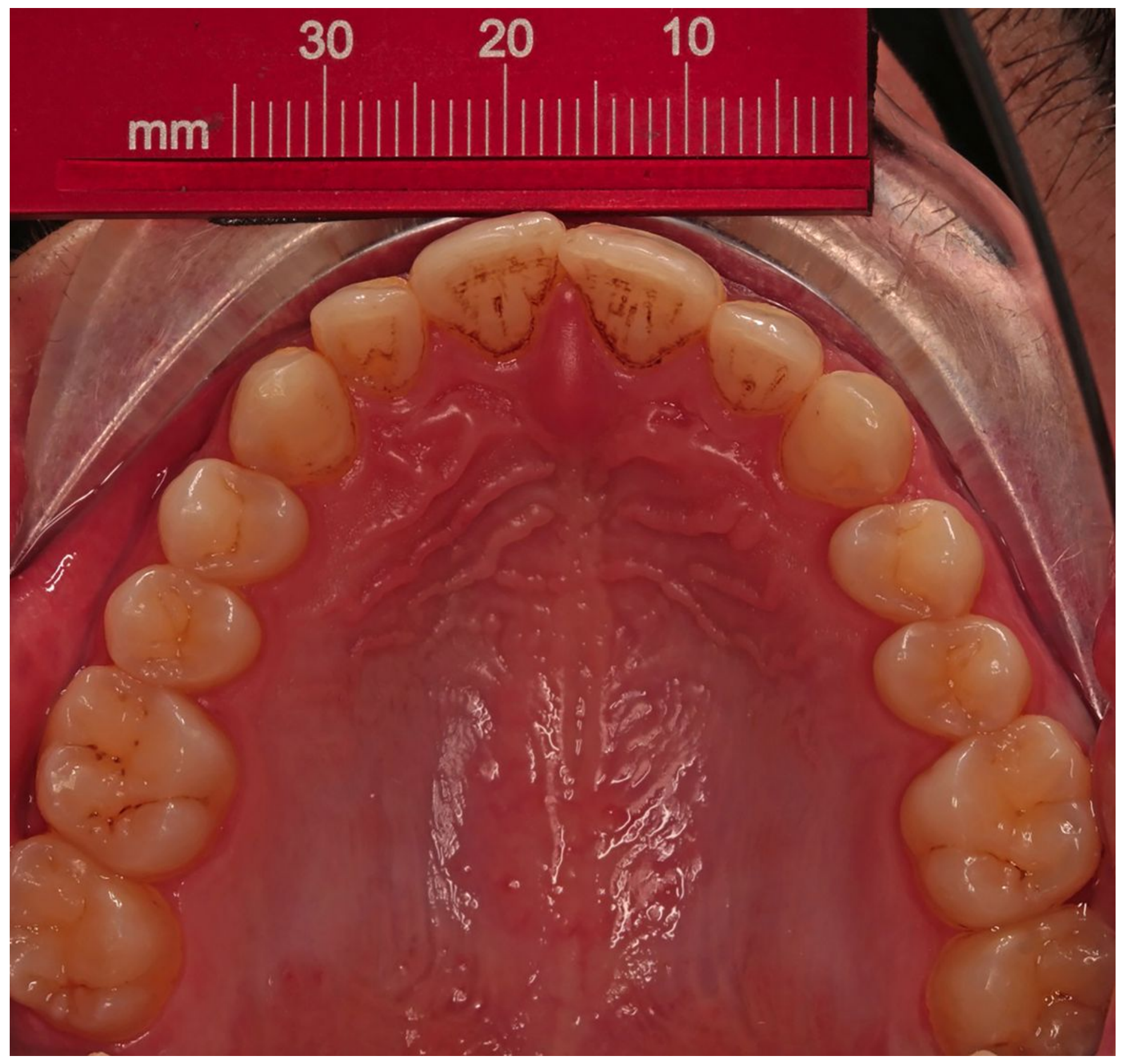

\section{Figure 2}

An intraoral photograph showing the embedded ruler for the calibration procedure. 